\title{
Mulheres na economia solidária: possibilidade de reconhecimento e emancipação social
}

\author{
Jaqueline Pereira de Oliveira \\ Mestranda do programa de pós-graduação em sociologia da UFG \\ jaquelineoliveira_@hotmail.com
}

\begin{abstract}
Resumo $\mathrm{O}$ artigo em questão tem por objetivo acentuar as mudanças no mercado de trabalho na sociedade contemporânea. Nesse sentido, destaca o trabalho feminino que, de longa data, sofre as mais diversas formas de desvalorização. As mulheres, cada vez mais, tornam-se responsáveis por subsidiar financeiramente suas famílias, e são elas também as que mais sofrem as conseqüências do desemprego ou do subemprego. Considerando tais aspectos, os empreendimentos de economia solidária são tidos como resposta a esse sistema que gera tanto uma desigualdade social, quanto uma desigualdade sexual no mundo do trabalho. Essas associações, além de propiciar a produção de renda, também possibilitam uma maior autonomia, auto-estima e participação democrática das mulheres, que é um pré-requisito fundamental da economia solidária.
\end{abstract}

Palavras-chave: economia solidária; trabalho feminino; emancipação social; autonomia e reconhecimento.

\section{Introdução}

$\mathrm{C}$ om o Desenvolvimento do sistema Capitalista é possível vislumbrar mudanças consideráveis na vida social, sobretudo no campo do trabalho. A lógica capitalista pressupõe que os mais aptos, tanto técnica quanto intelectualmente, sejam absorvidos pelas modernas estruturas do trabalho, ao passo que os que são destituídos desses pré-requisitos são vistos como inúteis e são lançados para as margens da vida social, acentuando ainda mais a desigualdade social.

O desenvolvimento técnico-cientifico, os processos de globalização, a descentralização dos processos produtivos, são fatores que alteraram fundamentalmente as relações de trabalho e a interação dos atores sociais. Nesse contexto, é lícito destacar as conseqüências desse movimento na vida dos indivíduos e como eles articulam iniciativas como forma de driblarem a situação de desemprego, exclusão e pobreza.

Nesse contexto, é lícito destacar o papel do trabalho feminino no âmbito dessas transformações. Além de mudanças no âmbito político, econômico e social, percebem-se também mudanças nos aspectos culturais. Anteriormente, o trabalho feminino restringia-se ao cuidado com o lar e com os filhos, porém, no contexto contemporâneo está havendo um movimento em que as mulheres são, cada vez mais, responsáveis por subsidiar financeiramente seus lares, não obstante, elas estão delineando sua presença no mercado de trabalho.

A inserção das mulheres nas relações de trabalho não constitui um evento simples, ao contrário, ele é investido de várias problemáticas. Além de uma desigualdade de cunho social, as mulheres são vítimas da desigualdade de sexo nas relações de trabalho, elas são, na maioria das ve- 
zes, as maiores vítimas do desemprego, e quando estão empregadas são submetidas ao trabalho doméstico ou às mais variadas formas de trabalhos, que são caracterizados como precários, pois além de não conferir a elas os direitos constitucionalmente garantidos, ainda não promovem a emancipação e o reconhecimento.

O desemprego, a precarização, a tão intensa desigualdade social e de sexo, e a exploração nas relações de trabalho, fomentam movimentos que são iniciados pelos trabalhadores: os sindicatos, as cooperativas, as associações solidárias, entre outros. Pretende-se aqui destacar os empreendimentos de economia solidária como forma de resposta às mudanças ocorridas na vida social centrada nas relações de trabalho. Esses empreendimentos abrangem diversos setores e podem ser consolidadas por diversas formas. Esse artigo tem o intuito de destacar a prática cooperativa como fio condutor das questões propostas.

O cooperativismo e o desenvolvimento industrial surgiram concomitantemente. O cooperativismo nasceu como forma de amenizar os inúmeros problemas que se fizeram presentes na estrutura do trabalho com o advento da revolução industrial, tais como o desemprego, produção em massa, a exploração, entre outros. A prática cooperativa, além de propiciar a geração de renda (vale lembrar que essa prática não objetiva o lucro), é também reconhecida por duas características fundamentais: a solidarização do capital e a autogestão (Alcantara, 2005).

Discute-se aqui o papel da economia solidária, no contexto de cooperativas, como resposta aos problemas que perpassam o universo do trabalho, sobretudo do labor feminino, e como esses empreendimentos tem sido uma possibilidade de geração de trabalho e renda, diminuindo, assim, as desigualdades e dando origem a processos de interações sociais vinculando solidariedade, participação democrática e emancipação social.

\section{Trabalho, emancipação e reconhecimento}

O trabalho se configura como uma esfera social básica, pois é com base nele que os indivíduos têm acesso às suas condições materiais mínimas de sobrevivência. É certo que garantir esses mínimos é de fundamental importância, mas não é mais suficiente como proposta de amenizar as injustiças sociais. $\mathrm{O}$ elemento do reconhecimento deve ser somado a essa discussão, para que o indivíduo seja integrado não só no plano material, mas também no âmbito da moral, isso implica dizer no discurso da dignidade humana. Nesse sentido, a categoria trabalho também tem um papel fundamental, pois pode ser entendido como espaço de constituição de identidade e de ação individual e coletiva.
No Brasil, o problema da desigualdade é oriundo da nossa constituição histórica, que teve por base uma estrutura escravocrata que persistiu mesmo após a tão esperada abolição e deixou à margem uma grande quantidade de indivíduos, no período denominados homens livres.

Desde os primórdios da colonização é possível verificar uma relação densa entre trabalho e desigualdade. Primeiramente, é importante analisar a constituição do trabalho escravo que é a base da qual se originou entre nós toda a situação de desigualdade e exclusão. Os escravos eram destituídos de qualquer direito, executavam trabalhos espúrios, indignos, sofriam as mais diversas formas de exclusão, violência e desconheciam qualquer referência à sua dignidade como seres humanos. O trabalho escravo é a forma de labor mais precária que a sociedade brasileira já conheceu, e, ainda hoje, restam resquícios dessa experiência entre nós.

$\mathrm{Na}$ virada do século XIX, verifica-se a passagem do Brasil rural para o Brasil urbano, em que se vislumbrava uma nova situação. Existiam não só os escravos, mas também os homens livres, pessoas não proletarizadas que formavam uma ralé que cresceu durante anos como seres totalmente dispensáveis (Franco, 1983). Nessa fase, existia uma intensa precarização nas relações de trabalho, uma vez que a maioria desses indivíduos eram analfabetos e não sabiam exercer qualquer outra atividade diferente daquelas que executavam anteriormente.

Nesse período, é possível perceber o quanto a pobreza fazia parte dessa sociedade em mudança, que se queria moderna e civilizada, mas que na verdade ainda carregava de forma muita intensa as marcas do ruralismo (Telles, 2001). Nessa perspectiva não havia uma preocupação com a questão social em termos de ordem social, mas sim em termos de ordem pública. Quando a intervenção do Estado se fazia presente, a ênfase que se predominava estava cunhada no paternalismo assistencialista da época, que não via a legislação social como um direito do trabalhador, mas sim como uma preocupação moral. Os direitos trabalhistas eram negados sob argumentos que faziam referência a um recente passado escravagista. Os trabalhadores continuavam sendo vistos como pobres, que careciam de tutela e não de direitos.

A situação começa a ganhar contornos diferenciados na história aberta da década de 1930, em que o Estado começa a atribuir um estatuto civil definido pelo trabalho. Por meio do trabalho, os indivíduos passam a ter existência civil e se transformam em cidadãos do trabalho, a quem o Estado oferecia a proteção dos direitos sociais que, de certa forma, neutralizavam as marcas da pobreza e da desigualdade. Esse fato representa uma melhoria da situação, mas não é visto como uma medida eficaz, pois existia um grande número de pessoas que não tinham acesso ao trabalho regular. Desse 
modo, ficavam à margem todos os que eram subempregados, trabalhadores domésticos, autônomos, mulheres e crianças. Aqui se configura a cidadania regulada, ou seja, os direitos eram concedidos somente àqueles que tinham registro em carteira (Santos, 1994).

O trabalho regular ainda é, na sociedade contemporânea, um dos pré-requisitos para se ter acesso aos direitos sociais básicos. Não obstante, é preciso repensar a situação daqueles que não conseguem ter acesso a um trabalho formal. Na sua grande maioria, são os que vivem em situação de extrema pobreza, pois não conseguem reunir nem mesmo o mínimo necessário para a sua sobrevivência e a de seus familiares.

\section{Mulheres e a precarização do trabalho}

As mudanças políticas e econômicas dos últimos tempos fizeram com que ocorressem mudanças nas relações de trabalho. Entre essas mudanças podemos destacar as novas tecnologias de produção que, de um lado, modernizaram o processo produtivo e, de outro, extinguiram vários postos de trabalho, contribuindo para o aumento do desemprego. É importante situar também o processo de globalização, que favoreceu trocas financeiras nos mercados globais, propiciou a descentralização produtiva das atividades de serviço, formação de redes empresariais, entre outras. Porém, é possível perceber as consequiências que tal processo acarreta sobre a sociedade, sobretudo sobre a esfera do trabalho.

A globalização é um processo que fomenta o crescimento, porém esse crescimento não é acompanhado da geração de empregos. Ao contrário, uma das conseqüências mais acentuadas do processo de globalização é a diminuição contínua dos postos de emprego (Pochmann, 1999). Além disso, verifica-se que esse processo acarreta uma desigualdade imensa entre países ricos e pobres, acentuando, assim, os altos índices de pobreza que nos últimos tempos têm afetado especialmente as mulheres, que são as primeiras vítimas do desemprego e da precarização das relações de trabalho.
Esse conjunto de fenômenos tem afetado todos os setores produtivos e pode ser caracterizado pelo conceito de flexibilização das relações de trabalho. A flexibilização vem acompanhada de mais dois outros processos: a desregulamentação e a precarização - eliminação dos direitos sociais.

Nesse sentido, cria-se uma massa totalmente destituída de qualquer qualificação - segundo as exigências do mercado em desenvolvimento - para ingressar nas estruturas modernas de trabalho. Trata-se de indivíduos totalmente dispensáveis para a sociedade, são vagabundos não se referindo àqueles que mendigam sem necessidade, conforme se pensava no século XVI, mas sim de vagabundos criados pelo processo de precarização e flexibilização do trabalho (Castel, 1998).

Nas últimas décadas, percebe-se uma acentuada inserção das mulheres no mercado de trabalho. Esse evento é resultado tanto de transformações de cunho econômico, quanto de cunho cultural. Anteriormente, o labor feminino se restringia aos trabalhos que visavam o cuidado com o lar e com a educação dos filhos, porém, nas últimas décadas as mulheres são cada vez mais as responsáveis por prover financeiramente seus lares. No entanto, percebe-se que existe uma desigualdade não só social, mas também de sexo nas relações de trabalho (Guérin, 2003). As mulheres continuam recebendo menos que os homens no exercício da mesma atividade, ocupam menos cargos de chefia, estão cada vez mais ocupando postos de trabalho marcados pela precarização e são as maiores vítimas do desemprego, conforme indica a tabela abaixo no comparativo de duas regiões no Brasil.

Nesse sentido, surgem diversos mecanismos com vistas a proporcionar a esses indivíduos que estão à margem da vida social a oportunidade de suprir suas necessidades básicas. Lima (2006) constatou que, com o processo de precarização, emergem duas formas de gestão: a informalidade e os empreendimentos solidários. É esse segundo movimento que será tratado aqui como possibilidade de reinserção social dos indivíduos que são vítimas do desemprego ou dos subempregos, sobretudo as mulheres que, como já foi apontado, têm uma participação cada vez mais intensa no campo do trabalho.

Tabela 1: Vínculos Empregatícios no Setor Formal - Brasil

\begin{tabular}{|l|l|l|l|l|l|}
\hline Região & Sexo & Frequência & $\%$ & REM MED R\$ & $\%$ \\
\hline \multirow{3}{*}{ Regiao Sudeste } & Masculino & 10.954 .785 & 60,39 & $14.978 .149 .796,34$ & 65,20 \\
\cline { 2 - 7 } & Feminino & 7.185 .383 & 39,61 & $7.993 .837 .486,94$ & 34,80 \\
\cline { 2 - 7 } & Total & 18.140 .168 & 100,00 & $22.971 .987 .283,28$ & 100,00 \\
\hline \multirow{3}{*}{ Regiao Centro-0este } & Masculino & 1.765 .481 & 61,59 & $2.611 .290 .574,71$ & 63,49 \\
\cline { 2 - 7 } & Feminino & 1.101 .080 & 38,41 & $1.501 .556 .627,50$ & 36,51 \\
\cline { 2 - 7 } & Total & 2.866 .561 & 100,00 & $4.112 .847 .202,21$ & 100,00 \\
\hline
\end{tabular}

Fonte: Rais 2006.

Elaboração: Própria 


\section{Economia solidária e suas possibilidades}

A economia solidária teve sua gênese logo depois da revolução industrial. Ela significou uma resposta aos inúmeros problemas ocasionados pela difusão das máquinas que ocorreu no período. Nesse processo, inúmeros trabalhadores foram destituídos de seus postos de trabalho por não terem a qualificação necessária para suprir as novas necessidades do processo produtivo. As que mais sofreram essas conseqüências foram as mulheres, pois eram as que menos tinham qualificação.

Com a implantação do capitalismo industrial se verificou um espantoso processo de empobrecimento dos artesãos e uma exploração contínua nas fábricas graças à ausência de limites legais. Essa situação ameaçava o bem-estar dos proletariados, fomentava a exploração do trabalho infantil e, ainda, prolongava de forma exorbitante a jornada de trabalho. Diante disso, percebia-se o debilitamento físico dos trabalhadores e sua elevada morbidade e mortalidade que comprometiam, de forma cada vez mais contínua, a produtividade.

A partir disso, surgem movimentos que têm por objetivo ser uma resposta a toda essa situação de exploração, desemprego e precariedade que tomava conta da vida e do trabalho dos proletarios. A economia solidária é um desses movimentos e teve repercussões enormes em várias partes do mundo.

Um exemplo importante foi o de Robert Owen, proprietário de um imenso complexo têxtil que começou a propor leis de proteção aos trabalhadores. Em vez de explorá-los, ele decidiu limitar a jornada de trabalho e proibir emprego de crianças para as quais construiu escolas. Esse tipo de tratamento dado aos trabalhadores, fez com que sua empresa obtivesse uma maior produtividade e, por conseqüência, maior lucratividade. Esse empresário tornou-se figura bastante admirada e todos queriam decifrar o segredo de como o dinheiro gasto com o bem-estar dos trabalhadores era recuperado sob a forma de lucro. As idéias de Owen eram divulgadas e logo seus discípulos começaram a por em prática seus ideais, criando sociedades cooperativas em todas as partes.

A cooperativa de Owean e as cooperativas formadas no fim de 1820 surgiram de greves ou foram criadas diretamente por grupos locais compostos por indivíduos que tinham salários rebaixados ou não conseguiam emprego, ou seja, emergiram da luta de classes e, muitas vezes, foram criadas para enfrentar e eliminar a empresa capitalista do mercado (Singer, 1998).

Segundo Singer (2002), o capitalismo se tornou dominante há tanto tempo que tendemos a tomá-lo como normal ou natural. Isso significa que a economia de mercado deve ser competitiva em todos os aspectos. Nesse sentido, a competição é boa de dois pontos de vista: ela permite aos consumidores escolher o que mais os satisfaz pelo menor preço, e ela faz com que o melhor vença, ou seja, os que prestarem melhores serviços aos consumidores é que serão os vencedores. Porém, a competição na economia tem sido criticada por causa de seus efeitos sociais, pois ela valoriza somente os vencedores, ao passo que os que não conseguem se destacar se tornam invisíveis. O capitalismo produz desigualdades crescentes, pois constrói imensas distâncias entre ganhadores e perdedores.

Para que fosse possível uma sociedade baseada nos princípios de igualdade, seria preciso que a economia fosse solidária em vez de competitiva. Seria necessário que houvesse cooperação ao invés de competição (Singer, 2002). A solidariedade na economia só podese realizar se for organizada igualitariamente pelos que se associam para produzir, comerciar, consumir ou poupar. Segundo Singer, o segredo desta proposta é a associação entre iguais em vez de contrato entre desiguais. $\mathrm{Na}$ empresa solidária, todos os sócios têm a mesma parcela do capital; nesse sentido, o mesmo direito de voto em todas as decisões. $\mathrm{Na}$ visão do autor, se toda a economia fosse solidária a sociedade seria muito menos desigual.

Um outro ponto importante aqui é o entendimento de que a competição e as desigualdades não são naturais. Ao contrário, elas resultam do modo de produção capitalista, cujos princípios são o direito a propriedade individual e à liberdade individual. Esses princípios dividem a sociedade em duas classes: a classe proprietária e a classe não proprietária que ganha a vida vendendo sua força de trabalho. Segundo Singer (2002), é essa forma de organização que dá origem a desigualdade e a competição.

A economia solidária é considerada um outro modo de produção, cujos princípios básicos são a propriedade coletiva ou associação do capital e o direito à liberdade individual. A aplicação desses princípios unifica a todos em uma única classe de trabalhadores. Segundo Singer, os resultados naturais dessa estruturação são: a solidariedade, a igualdade e a participação democrática. Esse conjunto de fatores faz com que os associados sejam mais conscientes, realizados e seguros.

Segundo Lima (2006), os empreendimentos solidários são uma alternativa ao assalariamento formal. Como Singer (2002) considera os empreendimentos solidários como uma possibilidade de rompimento com o modo de produção capitalista, Lima (2006) afirma que esses empreendimentos podem atuar a favor desse modo de produção. Esse autor destaca dois movimentos que vêm ocorrendo, sobretudo no Brasil, graças às mudanças ocorridas no campo do trabalho, quais sejam a informalidade e os empreendimentos solidários.

Lima (2006) ressalta que o termo informalidade foi por muito tempo vinculado a formas precárias de trabalho, ao subdesenvolvimento econômico e ao atraso social. E foi, na periferia, funcional ao sistema capitalista, pois garantia mão-de-obra barata aos indivíduos que sobreviviam em atividades de subsistência. 
Com o crescimento do desemprego a informalidade passa a ser produto de novos tempos flexíveis.

Segundo esse autor, os empreendimentos solidários dizem respeito a uma outra forma de variação na estrutura moderna do trabalho. Essas associações resultam de fábricas recuperadas ou organizadas para terceirização, ou ainda, como políticas de geração de renda. Segundo Lima (2006), no contexto atual esses empreendimentos fundamentam-se em uma contradição: de um lado, originam emprego e autonomia aos trabalhadores e, de outro, são funcionais ao sistema capitalista de produção.

Segundo o autor, esses paradoxos acentuam o caráter da flexibilização e precarização do trabalho. As cooperativas constituem trabalhos flexíveis por atenderem empresas quando estas precisam; como autônomas, correm o risco de abandonarem seus princípios autogestionários por causa do êxito no mercado. E caracterizam a precarização porque a maioria das cooperativas, segundo Lima (2006), são organizadas para atenderem as necessidades da terceirização, ou seja, para a redução de custos empresariais e, na maioria das vezes, significa, para os trabalhadores, a perda dos direitos trabalhistas. Nesse sentido, tornam-se falsas cooperativas. O termo refere-se à má utilização da legislação cooperativista com o objetivo principal de facilitar os mecanismos de terceirização e diminuição de custo da mão-de-obra para aquisição de maiores lucros. Essas falsas cooperativas estão longe de serem uma iniciativa dos próprios trabalhadores e não são comprometidas com os princípios da cooperação.

O posicionamento de Lima (2006) é extremamente crítico, pois os empreendimentos solidários podem significar tanto autonomia, quanto precarização. Autonomia, quando o trabalhador autogestionário propicia as condições necessárias de vida, trabalho e direitos. Todavia, seus aspectos positivos são limitados por causa de seu caráter informal.

Partindo de um ponto de vista diferente, Gaiger (2007) pontua algumas contribuições da economia solidária, sobretudo no âmbito da diminuição das desigualdades. Segundo esse autor, uma vez que essas organizações, ao se apoiarem na cooperação e ativarem circuitos de solidariedade, tendem a contribuir diretamente para com o fortalecimento dos seus membros propiciando a eles maior autonomia e confiança, e maiores possibilidades de promoção da igualdade.

Segundo Gaiger (2007), diante das limitações do crescimento econômico como instrumento eficaz na redução de pobreza e das desigualdades, ao lado da insuficiência das políticas paliativas os empreendimentos solidários de geração de renda e trabalho merecem atenção especial. Em primeiro lugar, eles têm por objetivo fortalecer a capacidade de ação dos empobrecidos. De modo efetivo, afastam-se da lógica dominante ao eliminarem a divisão entre trabalhadores e meios de produção, e entre produção e apropriação dos frutos do trabalho.
Gaiger (2007) concebe os empreendimentos solidários não só como fonte de geração de renda e trabalho, mas destaca também o quanto eles são importantes no fortalecimento de indivíduos ou grupos com capacidade de ação, ou seja, uma participação efetiva e democrática. A união em torno de objetivos comuns, juntamente com o espírito da solidariedade, coragem e vontade de mudar a própria vida, são instrumentos de transformação social e tornam a luta pela dignidade e emancipação social mais eficaz e abrangente.

Como já foi mencionado, as mulheres são, na maioria das vezes, as primeiras vítimas do desemprego, subempregos e da tão intensa desigualdade. Assim, os empreendimentos solidários são uma oportunidade efetiva para romper com essa realidade.

Guérin (2005) faz uma constatação interessante no que concerne à participação das mulheres nos empreendimentos solidários. Segundo ela, muitas dessas experiências são animadas por mulheres e destinadas às mulheres. Isso se deve ao fato de que as mulheres, na maioria das vezes, necessitam conciliar a vida profissional com a vida familiar, e têm maior dificuldade de ter acesso a propriedade e ao crédito. As mulheres, frequentemente, são as primeiras a se mobilizarem e a se auto-organizarem.

Os empreendimentos animados por mulheres são frequentes na área da alimentação, costura e da manutenção de roupas e panos, saúde, dos serviços de tratamento (creches), educação, da formação, entre outros. Essas diferentes iniciativas são, em primeiro lugar, uma resposta às necessidades cotidianas da grande maioria das mulheres. Porém, as organizações solidárias têm outra função fundamental além de gerar emprego e renda, pois essa não é suficiente para eliminar as desigualdades entre sexos.

Segundo Guérin (2005), as iniciativas solidárias são funcionais em três aspectos importantes que são, em conjunto, importantes para a diminuição ou completa extinção das desigualdades de sexo, sobretudo no âmbito das relações trabalhistas:

Ora, as iniciativas de economia solidária, que criam espaços intermediários entre o privado/doméstico e a vida pública, entre o monetário e o não-monetário, preenchem, de fato, três funções intersticiais importantes que podem favorecer a diminuição desses bloqueios. Em primeiro lugar, elas desempenham um papel de justiça de proximidade; ora, esta é essencial diante do caráter multidimensional da pobreza. Em segundo lugar, elas constituem espaços de discussão, de reflexão e de deliberação coletivas; elas se apresentam nesse aspecto como modo de acesso à fala pública para pessoas que geralmente não o têm. E, por meio da expressão e da reivindicação coletivas, elas podem participar da transformação das instituições, quer se trate da legislação ou das normas sociais. Em terceiro lugar, elas contribuem com a redefinição da articulação entre família, autori- 
dades públicas, mercado e sociedade civil, e participam da revalorização das práticas reciprocitárias; ora, essa redefinição e essa revalorização devem tornar possível que se lute contra as desigualdades intrafamiliares ao permitir que as mulheres, mas também os homens, conciliem melhor vida familiar e vida profissional (Guérin, 2005, p. 17 e 18).

Dessa forma, os empreendimentos solidários podem gerar resultados muito mais abrangentes que, de uma forma geral, são de extrema importância na constituição de medidas que possam favorecer a igualdade não só social, mas também de sexo.

No Brasil, percebe-se uma participação significativa de mulheres nos empreendimentos solidários. A Figura abaixo é resultado do primeiro mapeamento nacional realizado pela Secretaria Nacional de Economia Solidária (Senaes) e mostra o percentual de participação feminina nos empreendimentos solidários:

Tomando-se por base a visualização da figura, é possível perceber que as associações mistas são bem significativas, mas é possível perceber também que quando existe uma separação nos empreendimentos considerando o sexo, as mulheres estão na frente em relação aos homens. Esse fato possibilita a afirmar que os empreendimentos solidários merecem uma atenção especial, sobretudo no âmbito da discussão do desemprego ou subemprego feminino.

No Brasil, os empreendimentos solidários vêm ganhando um espaço cada vez maior. Talvez, seja pelo fato que no Brasil as taxas de desemprego sejam exorbitantes e, assim, os indivíduos ou grupos vão, da maneira como podem, procurando saídas para combater as conseqüências do desemprego e de todas as mazelas que o acompanham.

O primeiro mapeamento nacional de empreendimentos solidários permite visualizar a forma como esses empreendimentos estão se organizando em esfera nacional e possibilita perceber em quais regiões eles têm aparecido com maior intensidade.
A Tabela 2 expressa o número de empreendimentos solidários em cada um dos estados e regiões brasileiras.

Dos dados relacionados acima é possível destacar a quantidade de empreendimentos solidários encontrados na região nordeste, considerada por muitos como a região mais pobre do país. Nesse sentido, seria importante verificar qual o papel desempenhado por esses empreendimentos nesses locais atingidos por tão intensa desigualdade social que não é um evento natural, mas está fundamentado na questão distributiva de bens e serviços.

\section{Conclusão}

No Brasil se faz presente um potencial de crescimento facilmente identificado; porém, é possível perceber também problemas sociais que são incompatíveis com uma nação em desenvolvimento. A ineficiência do Estado em garantir os direitos de cidadania, a ausência de uma política eficaz de distribuição de renda, os grandes índices de analfabetismo, desemprego, subemprego e violência indica-nos que esse país ainda precisa caminhar muito para superar todas as mazelas sociais que aqui se fazem presentes.

As vítimas dessas mazelas, em sua grande maioria, criam alternativas para sobreviver diante de um cenário de tanta desigualdade e exclusão. Um exemplo notório desse fenômeno são os grupos de indivíduos que se organizam em associações solidárias.

Essas iniciativas não significam apenas uma medida de geração de emprego e renda, pois quando se organizam e efetivam o cumprimento de seus princípios básicos, ultrapassam as expectativas materiais de sobrevivência e, assim, fomentam iniciativas democráticas, ações conscientes e efetivas em busca do bem comum. Por outro lado, é preciso ter clareza de suas limitações. Como bem apontou Lima, os empreendimentos solidá-

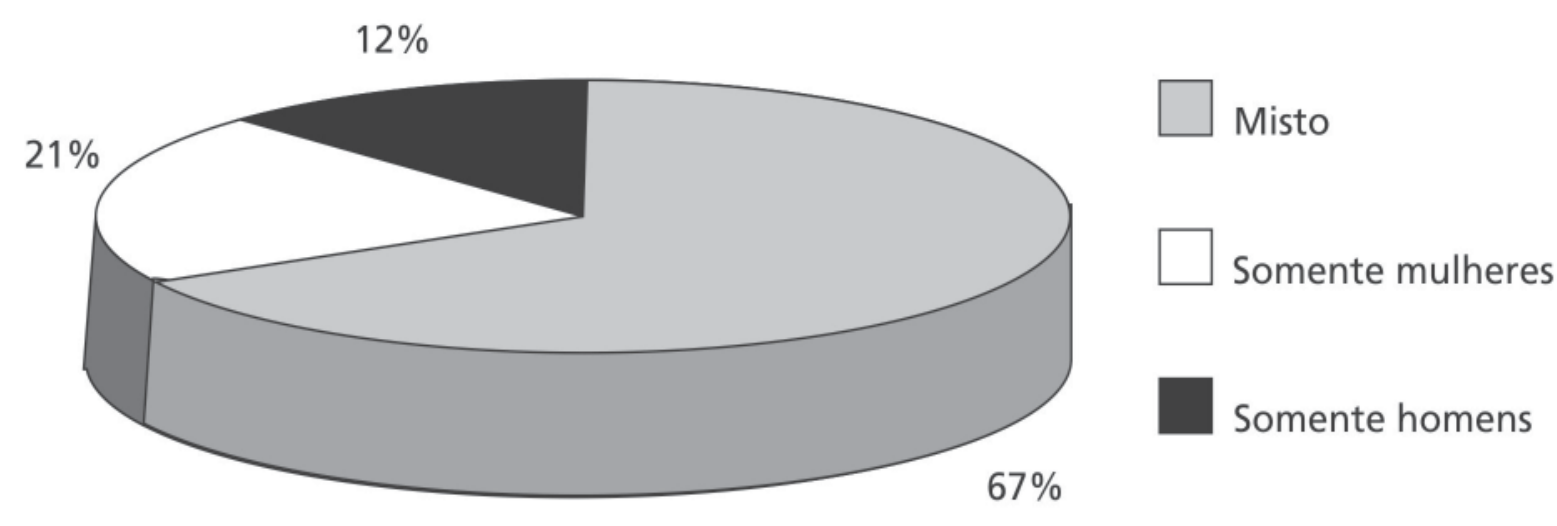

Figura 1: Primeiro Mapeamento Nacional de Economia Solidária

Fonte: Secretaria Nacional de Economia Solidária (Senaes). 
Tabela 2: Primeiro Mapeamento Nacional de Economia Solidária

\begin{tabular}{|c|c|c|c|c|}
\hline Estados/ Regiões & $\begin{array}{l}\text { Número de Empreendimentos } \\
\text { Econômicos Solidários }\end{array}$ & $\begin{array}{l}\text { \% Empreendimentos } \\
\text { Econômicos Solidários }\end{array}$ & Número de Municípios & $\begin{array}{l}\text { \% Municipios/ Total de } \\
\text { Municípios }\end{array}$ \\
\hline$R O$ & 240 & $1,6 \%$ & 40 & $75 \%$ \\
\hline$A C$ & 403 & $2,7 \%$ & 20 & $87 \%$ \\
\hline$A M$ & 304 & $2,0 \%$ & 32 & $51 \%$ \\
\hline$R R$ & 73 & $0,5 \%$ & 14 & $88 \%$ \\
\hline$P A$ & 361 & $2,4 \%$ & 51 & $35 \%$ \\
\hline$A P$ & 103 & $0,7 \%$ & 13 & $76 \%$ \\
\hline TO & 400 & $2,7 \%$ & 84 & $60 \%$ \\
\hline NORTE & 1.884 & $13 \%$ & 254 & $56 \%$ \\
\hline MA & 567 & $3,8 \%$ & 73 & $33 \%$ \\
\hline$P I$ & 1.066 & $7,1 \%$ & 83 & $37 \%$ \\
\hline$C E$ & 1.249 & $8,4 \%$ & 134 & $72 \%$ \\
\hline$R N$ & 549 & $3,7 \%$ & 77 & $46 \%$ \\
\hline$P B$ & 446 & $3,0 \%$ & 101 & $45 \%$ \\
\hline$P E$ & 1.004 & $6,7 \%$ & 129 & $69 \%$ \\
\hline$A L$ & 205 & $1,4 \%$ & 48 & $47 \%$ \\
\hline SE & 367 & $2,5 \%$ & 63 & $83 \%$ \\
\hline$B A$ & 1.096 & $7,3 \%$ & 153 & $37 \%$ \\
\hline NORDESTE & 6.549 & $44 \%$ & 861 & $48 \%$ \\
\hline MG & 521 & $3,5 \%$ & 101 & $45 \%$ \\
\hline$E S$ & 259 & $1,7 \%$ & 59 & $75 \%$ \\
\hline$R J$ & 723 & $4,8 \%$ & 82 & $88 \%$ \\
\hline$S P$ & 641 & $4,3 \%$ & 147 & $23 \%$ \\
\hline SUDESTE & 2.549 & $14 \%$ & 389 & $23 \%$ \\
\hline$P R$ & 527 & $3,5 \%$ & 109 & $27 \%$ \\
\hline SC & 431 & $2,9 \%$ & 133 & $45 \%$ \\
\hline$R S$ & 1.634 & $10,9 \%$ & 270 & $54 \%$ \\
\hline SUL & 2.592 & $17 \%$ & 512 & $43 \%$ \\
\hline MS & 234 & $1,6 \%$ & 25 & $32 \%$ \\
\hline MT & 543 & $3,6 \%$ & 91 & $65 \%$ \\
\hline GO & 667 & $4,5 \%$ & 127 & $51 \%$ \\
\hline$D F$ & 341 & $2,3 \%$ & 15 & $83 \%$ \\
\hline CENTRO- OESTE & 1.785 & $12 \%$ & 258 & $53 \%$ \\
\hline TOTAL & 14.954 & $100,0 \%$ & 2274 & $41 \%$ \\
\hline
\end{tabular}

Fonte: Secretaria Nacional de Economia Solidária (Senaes).

rios, assim como a informalidade, carregam a possibilidade de poderem ser duas coisas totalmente contrárias: serem produtoras de indivíduos autônomos, conscientes e democráticos e, por outro lado, serem simplesmente funcionais ao sistema capitalista de produção.

Segundo Andrioli (2002), o associativismo, desde que seja fiel a seus princípios fundamentais, é uma possibilidade de amenizar os graves problemas daqueles que são despossuídos de formas e conhecimentos para superar sua condição de marginalização social. Nesse contexto, insere-se a condição da mulher. As mudanças ocorridas na estrutura do trabalho, sobretudo a implantação e o desenvolvimento contínuo das máquinas, fez com que as mulheres ocupassem posições marginais dentro da estrutura moderna do trabalho. Segundo Hirata (2002), a substituição da mão-de-obra pouco ou não-qualificada por procedimentos automatizados tem conseqüências fundamentais sobre o trabalho feminino.

Essa afirmação se explica pelo fato de que as mulheres são consideradas incompetentes tecnicamente, não existem para elas cursos de formação nos ramos que empregam tradicionalmente homens. Nesse sentido, existe um processo que exclui as possibilidades de inserção de mulheres em indústrias informatizadas e quando o labor feminino se faz presente nessas estruturas é sempre ocupando funções que não necessitam do contato direto com o instrumental tecnológico.

Nesse sentido, os empreendimentos solidários aparecem como uma possibilidade de geração de trabalho e renda e se posicionam como um instrumento 
que reforça a organização social, a solidariedade, gera capacitação e trabalho e contribui para a promoção da cidadania e inclusão social, sobretudo das mulheres. E propicia ainda, por sua característica autogestionária, o exercício da participação, da convivência, constrói novas relações entre as pessoas e se torna um campo fecundo de luta por reconhecimento social.

Esse fato pode ser comprovado pela pesquisa de mestrado que está em andamento. Baseado em observações sistemáticas, foi possível perceber na cooperativa - Cooprec ${ }^{1}$ - que faz parte do universo empírico da referida pesquisa uma presença massiva das mulheres no trabalho executado pela organização. Foi possível perceber que a solidariedade entre elas ia além da execução dos trabalhos, pois existe uma convivência democrática que gera autonomia, auto-estima e reconhecimento.

Segundo seus idealizadores, os empreendimentos solidários devem se comprometer em transformar as relações competitivas em cooperativistas, fomentando valores como a ajuda mútua, a solidariedade, a responsabilidade e a luta pela efetivação dos direitos e cumprimento dos deveres do cidadão. Os membros de uma associação desse tipo devem estar dispostos a construir uma sociedade melhor. Nesse sentido, as organizações solidárias aparecem como uma possibilidade de organização e associação dos indivíduos, sobretudo das mulheres, com vistas a oferecer-lhes possibilidade de transformarem suas vidas através do trabalho, união e solidariedade.

1 Cooperativa de reciclagem de lixo localizada no Jardim Conquista - Região Leste de Goiânia.

\title{
Referências
}

ALCÂNTARA, Fernanda Henrique Cupertino. Introdução. Projetos, pluralismo e a modernidade contemporânea. O cooperativismo e a economia solidária no mundo. In: Economia Solidária: o dilema da institucionalização. São Paulo: Arte \& Ciência, 2005, p. 15-81.

ANDRIOLI, Antônio Inácio. Cooperativismo: uma resistência à exclusão. Rev. Espaço Acadêmico, n. 19, dez. de 2002.

CASTEL, Robert. As metamorfoses da questão social: uma crônica do salário. Petrópolis: Vozes, p. 1998, 95-135.

FRANCO, Maria Sylvia de Carvalho. Homens Livres na Ordem Escravocrata. 3. ed. São Paulo: Kairós, 1983, p. 21-106.

GAIGER, Luiz Inácio. A economia solidária diante das desigualdades. Revista Dados, n. 3, v. 50, 2007.

GUÉRIN, Isabelle. Introdução Geral. In: As mulheres e a economia solidária. São Paulo: Edições Loyola, 2005, p. 11-30. HIRATA, Helena. Novas tecnologias, qualificação e divi- são sexual do trabalho. In: Nova divisão sexual do trabalho? Um olhar voltado para a empresa e a sociedade. São Paulo: Boitempo, 2002, p. 221- 231.

LIMA, Jacob Carlos. Trabalho informal, autogestionário e gênero. Revista Sociedade e Cultura, v. 9, n. 2, 2006.

POCHMANN, Marcio. O trabalho sob fogo cruzado: exclusão, desemprego e precarização no final do século. São Paulo: Contexto, 1999, p. 25-48.

SANTOS, Wanderley Guilherme dos. Cidadania e Justiça: a política social na ordem brasileira. Rio de Janeiro: Campus, 1994.

SINGER, Paul. Uma utopia militante: repensando socialismo. Petrópolis: Vozes, 1999. p. 85-132.

Introdução à economia solidária. São Paulo: Editora

da Fundação Perseu Abramo, 2002.

TELlES, Vera da Silva. Pobreza e cidadania. São Paulo: Editora 34,2001, p.33-53.

\section{Women in Solidarity Economy: Possibility of Recognition and Social Emancipation}

\begin{abstract}
This article aims to highlight the changes in the labor market in contemporary society. In this context, it highlights female labor, which has constantly been undervalued. Women are increasingly becoming financially responsible for supporting their families; they also suffer the most the consequences of unemployment or underemployment. Therefore, solidarity economy is considered a reply to a system which generates both social and sexual inequality in the work place. These associations, besides providing income, they also allow for greater autonomy, higher self-esteem and women's democratic participation, which is an essential pre-requisite for economic solidarity.
\end{abstract}

Key words: Solidarity economy; female labor; social emancipation; autonomy and recognition. 